\title{
Economic and ecological sustainability of the thermal building envelope: a cross-European perspective
}

\author{
${\text { Tillman } \text { Gauer }^{1 *} \text {, and Björn-Martin Kurzrock }}^{1}$ \\ ${ }^{1}$ Technische Universität Kaiserslautern, Unit of Real Estate Studies, 67663 Kaiserslautern, Germany
}

\begin{abstract}
The building sector is crucial to reach the goals of common climate agreements. This paper contrasts three approaches to reduce emissions from typical residential buildings in Central Europe: the instalment of electric heat pumps (eHP), a thicker insulation of the thermal envelope and the encumbrance of a carbon tax. The use of less carbon intense fuels allows major savings of GHG emissions. An insulation thickness of $30 \mathrm{~cm}$ leads to $\mathrm{GHG}$ emission savings of $8 \%$ against a thickness of just $12 \mathrm{~cm}$, while total cost savings (LCC) remain negligible. The introduction of a carbon tax of up to $250 € / \mathrm{t}-\mathrm{CO}_{2}$-eq. does not necessarily result in a reduction of GHG emissions due to increased costs of construction. It was further found that the focus of legal building regulations on heating demand is sufficient for now but needs to be revised as carbon intensities continue to decrease. The heating then reduces its share of the GHG emissions from 85 to $55 \%$ for typical residential buildings. The paper closes with a general expression of the lifecycle costs of a building which is dependent on the factors above.
\end{abstract}

\section{INTRODUCTION}

The building sector is crucial to reach the goals of national and international climate agreements, e.g. the Paris Agreement. Literature shows that for new residential buildings the majority of emissions are caused by operating the building, while construction and deconstruction contribute less significantly. [1] This is mainly due to higher insulation standards that have evolved over the past years. Emissions from operation mainly result from heating, mainly using fuel oil and natural gas. Nowadays, as latest statistics e.g. from Germany show, electric heat pumps (eHP) and natural gas (NG) have become the most common heating systems for new buildings in Central Europe. [2] Electricity is produced very differently between countries and sometimes even within countries, which results in a large range of emissions for eHP. To reduce the emissions from operating the building two different approaches exist. On the one hand, a higher insulation reduces emissions during operation but results in higher emissions for construction. On the other hand, a less GHG intensive fuel reduces the emissions during operation without higher insulation standards. This paper contrasts three approaches to reduce emissions from typical residential buildings

* Corresponding author: tillman.gauer@bauing.uni-kl.de 
in Central Europe: the instalment of electric heat pumps (eHP), a thicker insulation of the thermal envelope and the encumbrance of a carbon tax.

\section{Investigated cases, methodology and assumptions}

\subsection{Investigated cases}

The investigation relates to a residential building representative for Central Europe. The three-storey building has a total floor area of $712.8 \mathrm{~m}^{2}$ and consists of 36 standardized rooms. The standardized rooms are based on DIN EN ISO 13791 to allow for a simulation of the heating demand in different cases.

The construction and insulation of the thermal envelope is in accordance with the German regulation for newly built buildings, EnEV16, which is in compliance with European directives. The outer walls consist of a load-bearing structure made of concrete with a thickness of $25 \mathrm{~cm}$ and an insulation layer of $12 \mathrm{~cm}$. For the latter, different thicknesses will be applied in the investigation. The other parameters of the thermal envelope remain the same as they are much more cost-intensive (windows) or delimit a room with higher temperatures than the environment, such as the top floor ceiling.

The investigation presumes a humid continental climate. ${ }^{\dagger}$ This climate is representative for big parts of Europe, i.e. the total area of Austria, Bosnia and Herzegovina, Bulgaria, Czech Republic, Denmark, Germany, Hungary, Poland, Serbia, Slovakia, Slovenia and Romania. Precisely, the weather scheme of Potsdam (TRY 4) is used.

\subsection{Methodology and assumptions}

The GHG emissions and non-renewable primary energy demand, along with other emissions, are the result of a bottom-up lifecycle analysis (LCA) for the representative building defined above. ${ }^{\ddagger}$ While the quantities of the different building part, e.g. roofs and walls, stem from the assumed geometry and used materials, the emission factors for the materials are based on ökobau.dat. ${ }^{\S}$ While the emission factors for natural gas are as well based on the ökobau.dat the emission factors for electricity are taken from [4] and [5].

The economic balance, the lifecycle costing (LCC), relates to the same structure and input data as the LCA. Above this, the LCC accounts for an assumed inflation of prices and present values of investments. The assumed inflation rate is $2 \%$ p.a. for building parts and $4 \%$ p.a. for energy. The interest rate for funds is set to $2 \%$ p.a. Further details can be found in [1] and [6]. Present values (PV) express all costs and economic effects associated with the building in current terms. ${ }^{* *}$ As prices for costs of construction vary significantly between different countries corresponding factors are used based on [7]. Both analyses assume a useful life for the building of 75 years.

In order to evaluate the ecologic and economic impacts, two phases of the LCA and LCC are balanced. The first covers all costs and emissions during construction, refurbishment and demolition. The second accounts for the heating of the building.

In addition to the prices for the fuels used, costs for the emission of GHG are accounted for. These costs would, most likely, be direct imposts on the fuel and based on their carbon intensity (CI). This would allow to actively influence the choice of fuels used for heating

\footnotetext{
$\dagger$ The warm summer subtype (Dfb) is presumed with warm summers and cold winters.

* Further results, e.g. for different construction types or emissions, are presented in [1]. $\S$ Ökobau.dat is a database for emission factors over the full lifecycle of building products.

${ }^{* *} \mathrm{PV}$ is the amount of money that needs to be invested at current to cover future payments.
} 
the building. Based on [10] and [11] carbon tax between 5 and $250 € / \mathrm{t}-\mathrm{CO}_{2}$-eq. are assumed. In literature, prices even exceeding $250 € / \mathrm{t}-\mathrm{CO}_{2}$-eq. can be found. [12]

In order to investigate the impact of an eHP, the maximum range of factors are calculated from three different representative CI and three SPF, taken from [4] and [13], see Table 1. The three bold emission factors are considered for the further investigation. The emission factor for natural gas also includes conversion losses, from primary to end energy, of $10 \%$ and adds up to $265 \mathrm{~g} \mathrm{CO}_{2}$-eq. $/ \mathrm{kWh}_{\text {net }}$.

Table 1. GHG emission factors for net energy $\left[\mathrm{g} \mathrm{CO}_{2}\right.$-eq. $\left./ \mathrm{kWh}_{\text {net }}\right]$.

\begin{tabular}{|c|c|c|c|c|}
\hline \multirow{2}{*}{$\begin{array}{c}\text { Carbon intensity }(\mathbf{C I}) \\
{\left[\mathbf{g ~ C O}_{\mathbf{2}} \text {-eq./ }_{\left.\mathbf{k} W h_{\text {net }}\right]}\right.}\end{array}$} & \multicolumn{3}{|c|}{$\begin{array}{c}\text { Seasonal performance } \\
\text { factor (SPF) }[-]\end{array}$} \\
\cline { 3 - 5 } & Sample countries & $\mathbf{2}$ & $\mathbf{3}$ & $\mathbf{4}$ \\
\hline $\mathbf{3 0 0}$ & Austria, Denmark, Slovenia & 150 & $\mathbf{1 0 0}$ & 75 \\
\hline $\mathbf{6 0 0}$ & Bulgaria, Czech Republic, Germany & 300 & $\mathbf{2 0 0}$ & 150 \\
\hline $\mathbf{9 0 0}$ & Poland & 450 & $\mathbf{3 0 0}$ & 225 \\
\hline
\end{tabular}

\section{Results and discussion}

\subsection{Substitution of carbon intense natural gas with electricity}

The costs and emissions for heating depend on the net energy demand for heating. The initially investigated building has a specific heating demand of $48 \mathrm{kWh} /\left(\mathrm{m}^{2} . \mathrm{a}\right)$.

Figure 1 shows the total GHG emissions during the lifecycle of the building. It can be seen that the CI of the used fuel has a significant impact on total emissions. In contrast, the construction contributes only about $168 \mathrm{t} \mathrm{CO}_{2}$-eq., equivalent to 18 to $40 \%$ of the total emissions. Heating is the major contributor to the total GHG emissions of the building. Furthermore, the use of eHP is, for nearly all cases, beneficial compared to the use of natural gas. For the following, the emissions of NG are assumed to be similar to an eHP with a GHG emission factor of 300 , as can be seen from Figure 1.

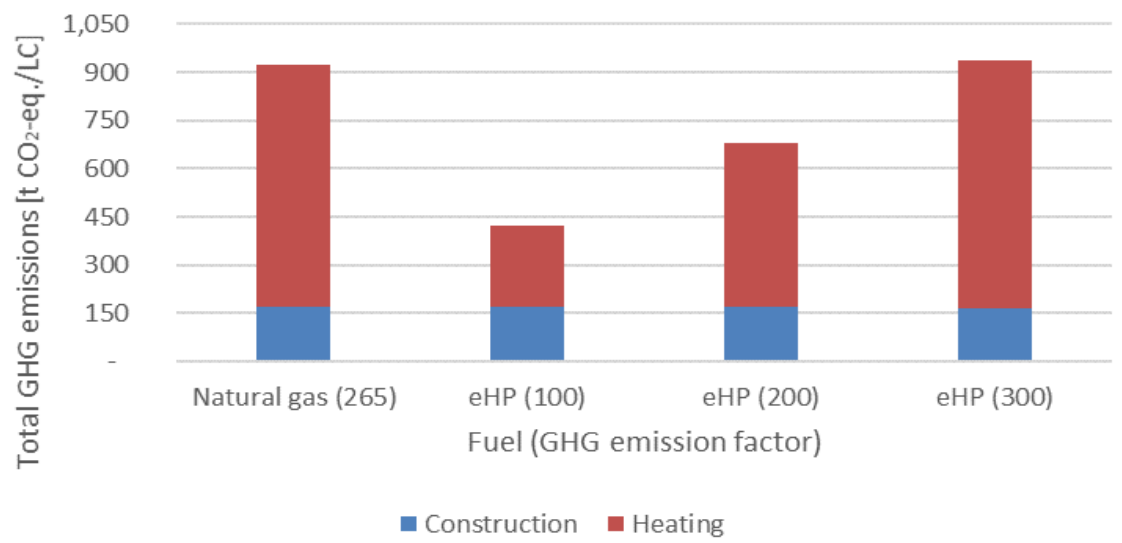

Fig. 1. Total GHG emissions of the sample building.

\subsection{Electric heat pumps and increased insulation}

In order to reduce the heating demand of a building, further insulation can be added to the building envelope. Here only the outer walls are refurbished which leads to two opposing trends. On the one hand, the heating demand decreases and thus the emissions due 
to heating. On the other hand, the emissions from construction increase. Figure 2 shows the impact of the variation of the insulation thickness. As in Figure 1, for most cases, heating is the main contributor to the total emissions of $\mathrm{GHG}$, ranging up to $84 \%$. Only for an emission factor of $100 \mathrm{~g}-\mathrm{CO}_{2}$-eq. $/ \mathrm{kWh}_{\text {net }}$ the share of heating decreases to 55 to $64 \%$.

As can be seen, the share of construction in total GHG emissions grows with increasing insulation and decreasing emission factors. This is mainly due to the fact that additional insulation has no significant impact on total emissions. The increase of construction for an additional $34 \mathrm{~cm}$ is only $2.6 \%$. In contrast, the heating demand is reduced by $16.5 \%$. In addition, Figure 2 shows that there is no minimum resulting in a technically feasible insulation thickness. Moreover, for any insulation thickness the use of a fuel with a lower carbon intensity is more beneficial than increasing insulation.
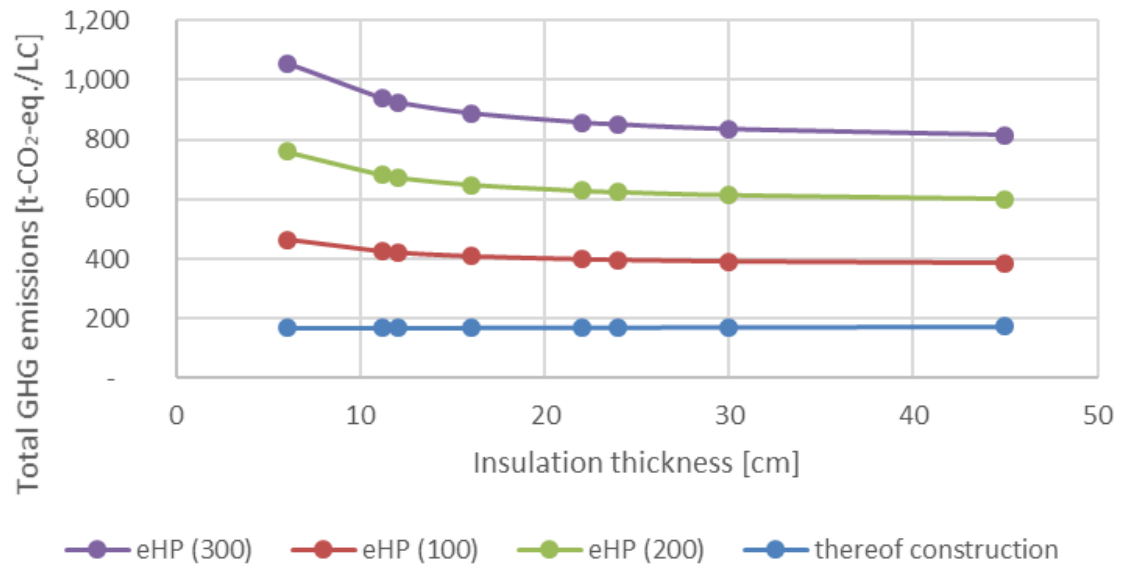

$-\operatorname{eHP}(200)$

$\longrightarrow$ thereof construction

Fig. 2. Total GHG emissions over insulation thickness of the sample building.

\subsection{Costs of construction and heating}

In contrast to the GHG emissions, which are of special public interest, the direct costs are most important for building owners and users. The price for net energy depends on the fuel price and the efficiency of conversion. From a price range for electricity of 0.1 to $0.3 € / \mathrm{kWh}_{\mathrm{el}}[14]$, as in Table 1, prices for net energy range between 0.15 and $0.03 € / \mathrm{kWh}_{\text {net }}$. Thus, prices of $0.05,0.075$ and $0.1 € / \mathrm{kWh}_{\text {net }}$ are considered in the further investigation.

Figure 3 indicates the total costs (LCC) as a function of the insulation thickness. In contrast to emissions, the PV of construction accounts for about $90 \%$ of the total costs. The costs for heating sum up to PVs of 56,000 to $155,000 €$. While the costs for construction increase only very little by the thickness of the insulation, the costs for heating decrease asymptotically. Those two behaviours lead to the effect, that the total costs have a (global) minimum. This minimum is, depending on the price of energy, at an insulation thickness of 15 to $25 \mathrm{~cm}$. For each of the investigated prices, the total costs vary only negligibly by less than $3 \%$ compared to the minimum. When only considering insulation thicknesses between $12 \mathrm{~cm}$ and $45 \mathrm{~cm}$ the change is less than $1 \%$. Equivalent insulations thicknesses of $12 \mathrm{~cm}$ can be found in current legal regulations for new buildings, such as the German EnEV. 


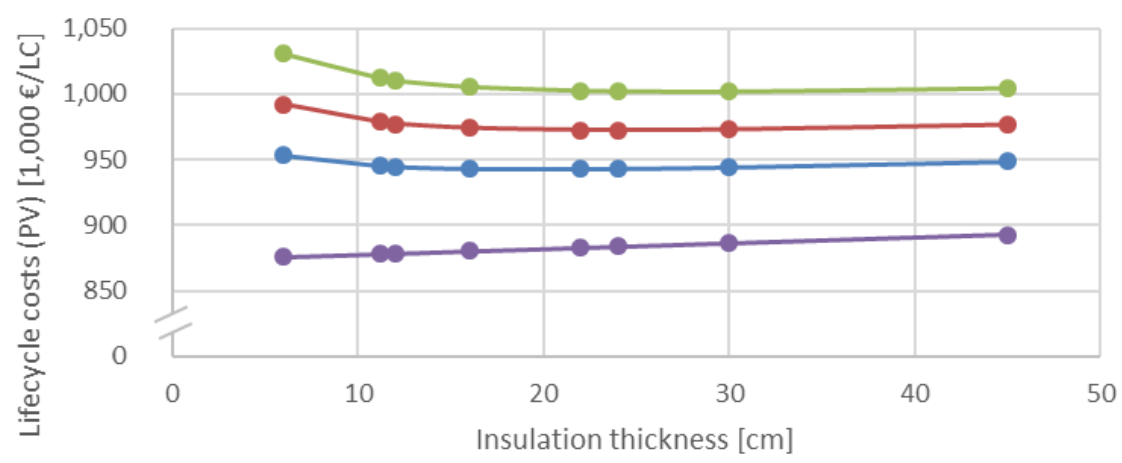

$\longrightarrow 0.05 € / \mathrm{kWhnet} \longrightarrow 0.075 € / \mathrm{kWhnet} \longrightarrow 0.1 € / \mathrm{kWhnet} \longrightarrow$ - thereof construction

Fig. 3. Costs over insulation thickness of the sample building.

\subsection{Taxation of GHG emissions}

In order to reduce emissions, the effects of a taxation mechanism shall be investigated. Such Pigouvian tax increase the price for energy, depending on its carbon intensity. ${ }^{\dagger}$ Thus, the tax makes low carbon intense fuels more cost efficient. The considered rates of the carbon tax range from 0 to $250 € / \mathrm{t}-\mathrm{CO}_{2}$-eq. The assumed energy price is $0.075 € / \mathrm{kWh}_{\text {net }}$.

Within the mentioned range, higher tax rates lead to an increase of the total costs (LCC) with no significant shift of the optimal insulations thickness given a typical carbon intensity of $200 \mathrm{~g}-\mathrm{CO}_{2}$-eq. $/ \mathrm{kWh}_{\text {net }}$. A tax rate of up to $100 € / \mathrm{t}-\mathrm{CO}_{2}$-eq accounts for less than $2.5 \%$ of the total costs. Only if the tax rate rises to $250 € / \mathrm{t}-\mathrm{CO}_{2}$-eq. emission costs for varying insulation thicknesses contribute 5.4 to $6.4 \%$ to the total costs. For a carbon intensity of $300 \mathrm{~g}-\mathrm{CO}_{2}$-eq. $/ \mathrm{kWh}_{\text {net }}$ tax rates exceeding $130 € / \mathrm{t}-\mathrm{CO}_{2}$-eq. lead to a share of 4.4 to $5.1 \%$ of the total costs. For low carbon intense heating systems, the taxation of emissions has only a negligible influence of 2.8 to $3.3 \%$ on the total costs of the building.

\subsection{General calculation of costs}

It can be easily seen that the optimal insulation thickness (d) of a building, expressed by the total costs (LCC), is an optimisation problem depending on several parameters. In order to give a general solution for this optimisation, the cost function will be derived. The costs, as shown in Table 1, consist of the present values (PVs) of costs for construction $\left(\mathrm{PV}_{\mathrm{c}}\right)$, for heating $\left(\mathrm{PV}_{\mathrm{h}}\right)$ and for emissions $\left(\mathrm{PV}_{\mathrm{e}}\right)$ of the heating. These are all dependent on the thickness of the insulation. It can also be seen that the costs of heating and the cost of emissions depend on the annual energy demand. From Figure 3 functions for the costs of construction and heating can be derived. While the costs for construction are already expressed as PVs, the costs for heating and emissions must also be discounted. Therefore, the annuity present value factor (A) is used. Additional factors are used to account for regional differences in prices and emission factors. Equation (1) allows to estimate the optimal insulation thickness (d) in terms of PV of total costs (LCC) for a building using a set of local or national parameters. The coefficients of the first polynomial are the cost per insulation thickness $[€ / \mathrm{cm}]$. The other construction costs of the building add to

\footnotetext{
${ }^{\dagger}$ In order to not increase the general cost of living, the tax revenue should be used to decrease other costs making less carbon intense living more cost efficient.
} 
$873,377.30 €$. The coefficients of the second polynomial result from the simulations of the specified building and indicate the heating demand depending on insulation thickness. The formula, therefore, is specific for the sample building but could be adjusted to any other building for which a simulation of the heating demand is performed. Equation (1) may serve to estimate the impact of the parameters on the total costs (LCC) of a building. The first derivative of equation (1) set to zero and solved for d provides the cost-optimal insulation thickness.

$$
\begin{gathered}
P V(d)=\left(\mathrm{PV}_{\mathrm{c}}\right)+\left(\mathrm{PV}_{\mathrm{h}}\right)+\left(\mathrm{PV}_{\mathrm{e}}\right) \\
=(424.61 * d+873,377.30) * \mathrm{RF}_{\mathrm{c}} \\
+\left(2.14 * d^{4}-244.85 * d^{3}+10,505.96 * d^{2}-206,908.38 * d+3,877,677.80\right) \\
* \mathrm{~A} *\left(\mathrm{RF}_{\mathrm{h}} * \mathrm{P}_{\mathrm{h}}+\mathrm{RF}_{\mathrm{e}} * 10^{-6} * \mathrm{P}_{\mathrm{e}}\right)
\end{gathered}
$$

$\mathrm{d}$ : Thickness of insulation $[\mathrm{cm}]$

$\mathrm{P}_{\mathrm{h}}$ : Price of heating $\left[€ / \mathrm{kWh}_{\text {net }}\right]$

$\mathrm{P}_{\mathrm{e}}$ : Price of emissions [€/t- $\mathrm{CO}_{2}$-eq.]

$\mathrm{RF}_{\mathrm{c} / \mathrm{h}}$ : Regional factor of the construction costs/heating demand of the building [-] $\mathrm{RF}_{\mathrm{e}}$ : Regional factor of the carbon intensity of the used energy [g-CO $\mathrm{CO}_{2}$-eq./ $/ \mathrm{kWh}_{\text {net }}$ ] $\mathrm{A}^{*}$ : Compound annual growth present value factor [-]

\section{Conclusion}

The LCA and LCC of a typical sample building in Central European countries show that the replacement of a heat generator using natural gas by an electric heat pump (eHP) is beneficial in terms of GHG emissions for nearly every combination of SPF and carbon intensity of electricity provision. Only the combination of very carbon intense electricity of $900 \mathrm{~g}-\mathrm{CO}_{2}$-eq./kWh, which can be found in just one of the twelve countries (Poland, Table 1), and an SPF below 3.5 leads to an increase of emissions. Thicker insulations lead to reduced GHG emissions but the costs remain largely the same. The total costs (LCC) of the sample building vary by less than $1 \%$ for insulation thicknesses between 12 and $30 \mathrm{~cm}$. The most feasible thickness is about $24 \mathrm{~cm}$ for most cases. The introduction of a carbon tax leads to a small shift of that minimum to $30 \mathrm{~cm}$ and to a further reduction of GHG emissions. Nevertheless, depending on the tax rate, the total costs increase by up to $20 \%$. For most of the cases the cost increase is about $7 \%$ and the reduction of GHG emissions is about $2 \%$.

The conclusion to be derived from this is that the first priority should be to use greener fuels for heating rather than enforcing higher insulation standards or a carbon tax for heating fuels. The presented equation allows to estimate the optimal insulation thickness in terms of total costs (LCC) for a building using a set of local or national parameters.

As heating accounts for about 55 to $85 \%$ of the GHG emissions of a building during its lifecycle it may be sensible to reduce emissions from heating through legal requirements. For carbon intensities below $100 \mathrm{~g}-\mathrm{CO}_{2}$-eq. $/ \mathrm{kWh}_{\text {net }}$, e.g. from green electricity and high SPF, half and more of the GHG emissions of a building can stem from the heating. A similar effect, also a potential advantage of eHP, is that the annual GHG emissions decrease with a decreasing carbon intensity of the electricity, without any doing of the building owner.

Further measures should be considered which aim to reduce the demand of heated space per person.

\footnotetext{
$\mathrm{k}^{*}\left(1-\mathrm{k}^{\mathrm{n}}\right) /(1-\mathrm{k})$, where $\mathrm{k}=(1+\mathrm{g}) /(1+\mathrm{i})$ with $\mathrm{g}=$ annual growth rate, $\mathrm{i}=$ discount rate and $\mathrm{n}$ $=$ useful life of the building.
} 


\section{References}

[1] T. Gauer, B.-M. Kurzrock: Zeitgemäße Wandkonstruktionen : Zur ökonomischen und ökologischen Nachhaltigkeit monolithischer Bauweisen. ZIÖ (2018)

[2] STATISTISCHES BUNDESAMT (Destatis): Bauen und Wohnen (Ed.): Baugenehmigungen / Baufertigstellungen von Wohn- und Nichtwohngebäuden (Neubau) nach Art der Beheizung und Art der verwendeten Heizenergie (2018)

[3] H. E. Landsberg, H. Lippmann, Kh. Paffen, C. Troll, E. Rodenwaldt, H.J. Jusatz: Weltkarten zur Klimakunde / World Maps of Climatology (1965)

[4] A. Moro, L. Lonza: Electricity carbon intensity in European Member States : Impacts on GHG emissions of electric vehicles, Transp. Res.: Transp. and Env. 64, p5-14 (2018)

[5] A. Esser, F. Sensfuss: Evaluation of primary energy factor calculation options for electricity (2016)

[6] A. Tersluisen, K. Nasrollahi, K. Bauer, M. Khalabari, N. Lebong, M. Shirani, B.-M. Kurzrock, T. Gauer, C. Völker, T. Lichtenheld: Untersuchung zeitgemäßer, monolithischer Wandaufbauten hinsichtlich bauphysikalischer, ökologischer und ökonomischer Eigenschaften (Forschungsinitiative Zukunft Bau F 3064) (2018)

[7] Baukosteninformationszentrum dt. Architektenkammern (Ed.): BKI Baukosten Regionalfaktoren 2019 für Deutschland und Europa (2018)

[8] D. Staniaszek: European Standards for Existing \& New Buildings (2015)

[9] Delft University of Technologie (Ed.): COllaboration for Housing Nearly ZeroEnergy RENOvation (COHERENO) (2016)

[10] J. Gerding: Emissionshandel: Deshalb sind die CO2-Preise so hoch. URL https://edison.handelsblatt.com/erklaeren/emissionshandel-deshalb-ist-der-co2-preisso-hoch/23098080.html (2018)

[11] OECD: Effective Carbon Rates (2018)

[12] V. Marchal, R. DellinkD. Van Vuuren, Ch. Clapp, J. Château, E. Lanzi, B. Magné, J. Van Vliet: OECD Environmental Outlook to 2050: Climate Change Chapter (2011)

[13] Ch. Russ,M. Miara, M. Platt, D. Günther, Th. Kramer, H. Dittmer, T. Lechner, Ch. Kurz: Feldmessung Wärmepumpen im Gebäudebestand (2010)

[14] EC (Ed.): Electricity prices for household consumers: biannual data (2018) 